\title{
Phycocyanin inhibits Helicobacter pylori-induced hyper-proliferation in AGS cells via activation of the ROS/MAPK signaling pathway
}

\author{
Yakun Bi ${ }^{1,2}$, Daoyan $\mathrm{Wu}^{1,3}$, Xiaojuan $\mathrm{Wu}^{1,3}$, Fei Wang ${ }^{1,3}$, Hang Yu ${ }^{1,3}$, Pan Liu ${ }^{1,3}$, Guzhen Cui ${ }^{1,3}$, \\ Zhenghong Chen ${ }^{1,3}$
}

${ }^{1}$ Key Laboratory of Microbiology and Parasitology of Education Department of Guizhou, School of Basic Medical Science, Guizhou Medical University, Guiyang, China; ${ }^{2}$ Department of Clinical Laboratory, The Maternal and Child Health Care Hospital of Guizhou Medical University, Guizhou Medical University, Guiyang, China; ${ }^{3}$ Key Laboratory of Endemic and Ethnic Diseases of Ministry of Education/Key Laboratory of Environmental Pollution Monitoring and Disease Control, Ministry of Education, Guizhou Medical University, Guiyang, China

Contributions: (I) Conception and design: Y Bi, D Wu, Z Chen; (II) Administrative support: Y Bi, G Cui; (III) Provision of study materials or patients: None; (IV) Collection and assembly of data: Y Bi, H Yu, P Liu; (V) Data analysis and interpretation: Y Bi, Wu, F Wang; (VI) Manuscript writing: All authors; (VII) Final approval of manuscript: All authors.

Correspondence to: Zhenghong Chen. Key Laboratory of Microbiology and Parasitology of Education Department of Guizhou, School of Basic Medical Science, Guizhou Medical University, Guiyang, China. Email: chenzhenghong@gmc.edu.cn.

Background: Reactive oxygen species (ROS)-induced oxidative stress (OS) and hyper-proliferation of gastric epithelial cells (GECs) due to Helicobacter pylori (Hp) infection are important mechanisms that lead to gastric carcinoma. Phycocyanin is a marine functional food additive with antioxidant and anti-inflammatory properties.

Methods: The flow cytometry was used to detect the effect of $150 \mu \mathrm{M}$ phycocyanin intervention on the cell cycle of human gastric adenocarcinoma cell line (AGS) infected with Hp. The transcriptomics of AGS cells intervened by $150 \mu \mathrm{M}$ phycocyanin for $24 \mathrm{~h}$ and infected by Hp were detected. Differential gene expression analysis was performed using a cutoff at the normalized gene expression $(\log 2)$ of 2 and a P-value of $<0.05$. Comparisons of the transcriptomes were made between the following groups: (I) AGS cells not infected with Hp and not using phycocyanin action and AGS cells infected with Hp only; (II) AGS cells not infected with Hp and not using phycocyanin action and AGS cells infected with phycocyanin action only; and (III) AGS cells infected with Hp only and phycocyanin treated and infected with Hp cells. c-myc and CyclinD1 was detected by quantitative real-time polymerase chain reaction (qRT-PCR) and immunoblotting. Phosphorylation and non-phosphorylation of c-Jun N-terminal kinase (JNK), extracellular signal-regulated kinase (ERK), and p38 Mitogen-activated protein kinase (p38MAPK) were detected by immunoblotting. Intracellular ROS was detected by immunofluorescence.

Results: Phycocyanin alleviates the Hp infection-induced increased cell viability and expression of cell cycle regulatory proteins c-myc and CyclinD1. Kyoto Encyclopedia of Genes and Genomes (KEGG) enrichment analysis revealed that the differentially expressed genes in phycocyanin-treated Hp-infected AGS cells were most significantly enriched in the mitogen-activated protein kinase (MAPK) signaling pathway. Phycocyanin could inhibit the Hp infection-induced phosphorylation of JNK, ERK, and p38MAPK and reduce the level of cellular ROS.

Conclusions: This study suggests that phycocyanin can regulate the ROS/MAPK signaling pathway and reduce c-myc and CyclinD1 expression to inhibit the hyper-proliferation of AGS cells. Phycocyanin may serve as an inhibitor of malignant progression of $\mathrm{Hp}$ infection-induced gastric disease.

Keywords: Helicobacter pylori (Hp); phycocyanin; proliferation; mitogen-activated protein kinase (MAPK); reactive oxygen species (ROS)

Submitted Nov 30, 2021. Accepted for publication Jan 27, 2022.

doi: $10.21037 / \mathrm{atm}-21-7045$

View this article at: https://dx.doi.org/10.21037/atm-21-7045 


\section{Introduction}

Helicobacter pylori $(\mathrm{Hp})$ infects up to $50 \%$ of the world's population and is classified as a class I carcinogen for gastric cancer $(1,2)$. Damage caused by cellular or tissue oxidative stress (OS) serves as the main trigger for gastritis associated with the development of human gastric cancer. Hp infection is an important factor that causes oxidative damage to human gastric mucosa (3). Reactive oxygen species (ROS) is an active component that plays an innate immune role in the human body. Hp strains contain a variety of virulence factors such as urease, vacuolating toxin, and neutrophil-activating protein $\mathrm{A}$, resulting in the production of ROS in many cell types, including epithelial cells (4). However, Hp has various defense mechanisms against external ROS attacks, the immune response can not eradicate bacteria in $\mathrm{Hp}$ infected gastric mucosa. When oxygen-free radicals increase in the body, they can act on proteins, lipids, and nucleic acids of body cells and damage them, resulting in diseases (5). The infection of epithelial cells by Hp results in excessive production of ROS which are closely associated with histological mucosal damage in the gastric epithelium (6). OS is a state of defense in which toxic ROS incapacitates endogenous host antioxidants. There is a whole defense system against ROSs damage in the human body, mainly some antioxidant enzymes. Under physiological conditions, the synergistic effect of antioxidant enzymes and antioxidants keeps oxygen-free radicals superficial. When its generation exceeds the body's ability to scavenge and repair, under pathological conditions, a variety of antioxidant enzymes in the body are required to remove excessive oxygen free radicals in time to protect tissues and cells from damage and excessive $\operatorname{ROS}(7,8)$. As a result, many studies have proposed that consumption of antioxidant-rich foods can counteract the damage caused by excess ROS to human health, thus reducing the risk of malignant progression of gastric diseases $(9,10)$.

Phycocyanin (PC), a blue photosynthetic pigment protein purified from Spirulina. Its principal function is to transfer excitation energy to the reaction center in photosynthesis. The blue color of the protein is due to the covalent binding of an open-chain tetrapyrrole ring auxiliary group on the peptide chain (11). Phycocyanin has been reported to inhibit the proliferation of various tumor cells, including breast cancer, colon cancer, cervical cancer, and non-small cell lung cancer (12-14). This is mainly due to its antioxidant and free radical scavenging effects. In pancreatic $\beta$-cells, phycocyanin reduces palmitate-induced
ROS overproduction and attenuates nuclear factor kappa gene binding $(\mathrm{NF}-\mathrm{\kappa B})$ receptor activator ligand-mediated intracellular ROS production in osteoblasts $(15,16)$. Phycocyanin has a variety of potent biological functions such as antioxidant $(17,18)$, anti-inflammatory $(19)$, and immunomodulatory (20) effects, making it one of the most recognized natural marine functional foods globally.

In this study, we learned that phycocyanin inhibits the Hp infection-induced hyper-proliferation in human gastric epithelial human gastric adenocarcinoma cell line (AGS). However, there are limited reports on the treatment of $\mathrm{Hp}$ infections with phycocyanin. Hence, in this study, we cocultured Hp with human gastric epithelial AGS cells and applied transcriptomic techniques to analyze the biological processes and signaling pathways involved in the significant enrichment of $\mathrm{Hp}$ infection-induced differentially-expressed genes (DEGs) in the absence and presence of phycocyanin. The conceivable mechanism of action of phycocyanin in the treatment of $\mathrm{Hp}$ infection was validated by various experimental techniques with the aim of laying a theoretical foundation for the application of phycocyanin in the future treatment modalities of $\mathrm{Hp}$ infection.

We present the following article in accordance with the MDAR reporting checklist (available at https://atm. amegroups.com/article/view/10.21037/atm-21-7045/rc).

\section{Methods}

\section{Cell line and culture conditions}

The human gastric adenocarcinoma cell line AGS (ATCC CRL 1739) was purchased from Shanghai Zhongqiaoxinzhou Biotech (Shanghai, China). The cells were grown in complete medium consisting of Rosewell Park Memorial Institute (RPMI) 1640 basal medium (Gibco; Thermo Fisher Scientific, Inc., MA, USA) supplemented with $10 \%$ fetal bovine serum (FBS, Thermo Fisher Scientific, Inc., USA). The cells were cultured at $37^{\circ} \mathrm{C}$ in a humidified atmosphere of $95 \%$ air and $5 \% \mathrm{CO}_{2}$.

\section{Cell culture with Hp infection}

The Hp ATCC26695 strain used in this study was a cagA+ and vacA+ positive standard strain. It was inoculated on chocolate agar plates in an anaerobic chamber (Oxoid, Ltd., Basingstoke, UK) containing 10\% sheep blood (Qingdao Hope Biol-Technology Co., Ltd., Qingdao, China). The agar plates were incubated at $37^{\circ} \mathrm{C}$ for $3-5$ days under 
microaerophilic conditions $\left(10 \% \mathrm{CO}_{2}, 85 \% \mathrm{~N}_{2}\right.$, and $\left.5 \% \mathrm{O}_{2}\right)$ with 95\% relative humidity (Micro Aerobic Bag; Mitsubishi Chemical Corporation, Tokyo, Japan). AGS cells were seeded and cultured overnight to reach $80 \%$ confluency. Prior to Hp infection, the cells were washed with antibioticfree culture medium. Hp cells were harvested from the chocolate agar plates, suspended in antibiotic-free RPMI 1640 medium supplemented with $10 \%$ FBS, and then added to the AGS cells.

\section{Cell proliferation assay}

AGS cell viability was determined using the trypan blue exclusion assay ( $0.2 \%$ trypan blue, Sigma, USA) to determine the cell count, and Cell Counting Kit8 (CCK-8) assays (thiazolyl blue) were purchased from Nanjingjiancheng (China) to determine the percentage of viable cells. Briefly, cells in the exponential phase of growth were harvested and seeded into 96-well plates at a density of 5,000 cells per well. The cells were pre-treated with $150 \mu \mathrm{M}$ phycocyanin-containing medium for $24 \mathrm{~h}$, and then cocultured with $\mathrm{Hp}$ at a concentration ratio (cells/bacteria 1:50) for another $24 \mathrm{~h}$. Subsequently, $10 \mu \mathrm{L}$ of CCK-8 solution was added into each well, and the absorbance was determined using a microplate reader (iMark, Bio-Rad Laboratories, USA) at $450 \mathrm{~nm} 1 \mathrm{~h}$ later.

\section{Cell cycle assay}

After being pre-treated with phycocyanin for $24 \mathrm{~h}$ and with treated $\mathrm{Hp}$ for $24 \mathrm{~h}$, the cells were harvested and fixed in $1 \mathrm{~mL}$ of $70 \%$ cold ethanol in tubes and incubated at $4{ }^{\circ} \mathrm{C}$ for at least $12 \mathrm{~h}$. The cells were centrifuged at 1,500 rpm for $5 \mathrm{~min}$, and the cell pellets were resuspended in $500 \mu \mathrm{L}$ of propidium iodide (PI)/ ribonuclease acid enzyme (RNase) staining buffer, incubated on ice for $30 \mathrm{~min}$, and washed twice with cold Phosphate Buffered Saline (PBS). Cell cycle distribution was measured using a FACS Calibur flow cytometer (Becton Dickinson, Franklin Lakes, NJ, USA).

\section{Cell apoptosis assay}

After treatment with $\mathrm{Hp}$ for $48 \mathrm{~h}$, the cells were harvested, washed twice with cold PBS, and resuspended in $500 \mu \mathrm{L}$ binding buffer. They were then were stained with $5 \mu \mathrm{L}$ Annexin V-fluoresceine isothiocyanate (FITC)/ PI according to the manufacturer's protocol (Roche, Mannheim, Germany). Stained cells were analyzed using
FACSCalibur (Becton Dickinson). The experiment was independently repeated thrice.

\section{RNA-Sequencing and bioinformatics analysis}

Briefly, after treatment with phycocyanin and Hp, total ribonuclease acid (RNA) was extracted using TRIzol reagent (Invitrogen, Thermo Fisher Scientific, Inc., MA, USA). Twelve micrograms of total RNA were used for analysis. Base calling was adopted to convert the original sequencing images to sequential data. Human genome sequences and gene annotations were obtained from the University of Calfornia SANTA CRUZ (UCSC) Genome Website (http://genome.ucsc.edu/). Differential gene expression analysis was performed using a cutoff at the normalized gene expression $(\log 2)$ of 2 and a $\mathrm{P}$-value of $<0.05$. After filtering the DEGs, Gene Ontology (GO) analysis was performed using the Database for Annotation, Visualization and Integrated Discovery (DAVID) bioinformatics program (https://david.ncifcrf.gov) for gene identification and annotation. To identify the functional groups and molecular pathways associated with the observed DEGs, RNASequencing data were further analyzed using the Kyoto Encyclopedia of Genes and Genomes (KEGG) database (https://www.genome.jp/). Sequence files and metadata for all samples used in this study have been submitted in the National Center for Biotechnology Information (NCBI) Sequence Read Archive (SRA) with accession number PRJNA496261.

\section{Quantification analysis by real-time quantitative polymerase chain reaction (RT-qPCR)}

After being pre-treated with phycocyanin for $24 \mathrm{~h}$ and infected with $\mathrm{Hp}$ for $8 \mathrm{~h}$, AGS cells were collected for RNA extraction. Total RNA was extracted using TRIzol reagent (Invitrogen). For each detected gene, $2 \mu \mathrm{g}$ of total RNA was reverse transcribed and quantified with a SYBR Green Real-Time PCR Master Mix Kit (TaKaRa, Dalian, China). Glyceraldehyde-3-phosphate dehydrogenase (GAPDH) was used as an endogenous control.

The primers used in the assays were as follows:

GAPDH forward 5'-ATCCCATCACCATCTTCCAG-3', reverse 5'-CCATCACGCCACAGTTTCCC-3'; MYC forward 5'-GGCTCCTGGCAAAAGGTCA-3', reverse 5'-CTGCGTAGTTGTGCTGATGT-3'; CCND1 forward 5'-GCTGCGAAGTGGAAACCATC-3', reverse 5'-CCTCCTTCTGCACACATTTGAA-3'; 
DUSP2 forward 5'-GGGCTCCTGTCTACGACCA-3', reverse 5'-GCAGGTCTGACGAGTGACTG-3'; GADD45A forward 5'-GAGAGCAGAAGACCGAAAGGA-3', reverse 5'-CACAACACCACGTTATCGGG-3'; FOSB forward 5'-GCTGCAAGATCCCCTACGAAG-3', reverse 5'-ACGAAGAAGTGTACGAAGGGTT';

FOSL1 forward 5'-CAGGCGGAGACTGACAAACTG-3', reverse 5'-TCCTTCCGGGATTTTGCAGAT-3'; MAP3K14 forward 5'-CGGAAAGTGGGAGATCCTGAA-3', reverse 5'-GGGCGATGATAGAGATGGCAG-3' .

The relative expression of each gene was then calculated and normalized by the $\Delta \Delta \mathrm{Ct}$ method. Each assay was performed in quadruplicate.

\section{Western blot analysis}

After pre-treatment with phycocyanin for $24 \mathrm{~h}$ and infection with Hp for $12 \mathrm{~h}$, the cells were collected for protein extraction. Proteins were extracted using RadioImmunoprecipitation Assay (RIPA) buffer with protease inhibitors (Roche, Basel, Switzerland) and quantified using the Bradford reagent (Biomed, Beijing, China). Equivalent amounts of protein were resolved on $10 \%$ sodium dodecyl sulfate polyacrylamide gels polyacrylamide gels and then electro-transferred to polyvinylidene difluoride (PVDF) membranes (Millipore, Germany). After blocking with 5\% Bovine Serum Albumin (BSA), the membranes were incubated with anti- c-Jun $\mathrm{N}$-terminal kinase (JNK)1/2 mouse antibody (Catalog No. 66210-1lg), anti- extracellular signal-regulated kinase (ERK) $1 / 2$ mouse antibody (Catalog No. 67170-1-lg), anti-p38 rabbit antibody (Catalog No. 14064-1-AP), anti-phosphoJNK1/2 rabbit antibody (Catalog No. 80024-1-RR), antiphospho-ERK1/2 rabbit antibody (Catalog No. 287331-AP), anti-phospho-p38 rabbit antibody (Catalog No. 4511), anti-phospho- inhibitor of nuclear factor kappa-B kinase alpha (p-IкB- $\alpha$ ) mouse antibody (Catalog No. 9246), anti-IкB- $\alpha$ rabbit antibody (Catalog No.4814), and antiGAPDH rabbit antibody (Catalog No. 10494-1-AP) at $4{ }^{\circ} \mathrm{C}$ overnight, followed by incubation with horseradish peroxidase-conjugated anti-rabbit Immunoglobulin $\mathrm{G}$ [ IgG (Catalog No. SA00001-2) or anti-mouse IgG (Catalog No. SA00001-1)] secondary antibodies. The anti p65 rabbit antibody, anti-phospho-IкB- $\alpha$ rabbit antibody, and anti IкB- $\alpha$ mouse antibody were purchased from Cell Signaling Technology (Danvers, MA, USA), and other antibodies were purchased from Proteintech (Wuhan, China). Signals were detected using enhanced chemiluminescence
(Millipore, USA). Cell collection and protein extraction were performed as described previously.

\section{Measurement of intracellular ROS generation}

Intracellular ROS were detected using the total ROS assay kit (Jiancheng, Nanjing, China). Briefly, 1,000 cells per well were cultured for $12 \mathrm{~h}$ in a laser confocal cell culture dish pretreated with phycocyanin for $24 \mathrm{~h}$ and infected with $\mathrm{Hp}$ for $4 \mathrm{~h}$. The cells were then incubated with 2, 7-dichlorofluorescin-diacetate (DCFH-DA) (Jiancheng, Nanjing, China) for $30 \mathrm{~min}$. Following treatment, the cells were washed with serum-free medium three times and exposed to the indicated treatments. ROS levels were analyzed and imaged using a fluorescence microscope (Olympus Corporation, Tokyo, Japan).

\section{Measurement of 065 generation}

A total of 1,000 AGS cells per well were cultured for $12 \mathrm{~h}$ in a laser confocal cell culture dish, after being pre-treated with phycocyanin for $24 \mathrm{~h}$ and infected with Hp for $12 \mathrm{~h}$. The cells were then fixed with $4 \%$ paraformaldehyde for $20 \mathrm{~min}$ and permeabilized with $0.3 \%$ Triton X100 for $15 \mathrm{~min}$ at room temperature. Next, the cells were blocked with goat serum solution for $1 \mathrm{~h}$, followed by anti $\mathrm{p} 65$ rabbit antibody (Catalog No. 8242, Cell Signaling Technology, Danvers, MA, USA) at $4{ }^{\circ} \mathrm{C}$ overnight in a humidified chamber. The cells were thoroughly rinsed and stained with a fluorescent secondary antibody for $1 \mathrm{~h}$. Finally, the nuclei were stained with 2-(4-Amidinophenyl)6-indolecarbamidine dihydrochloride (DAPI) for $10 \mathrm{~min}$ and imaged using a fluorescence microscope (Olympus).

\section{Statistical analysis}

Statistical analysis was performed using GraphPad Prism software (GraphPad Software Inc., La Jolla, CA, USA). Statistical significance was labeled with an asterisk (*, $\left.\mathrm{P}<0.05 ;{ }^{* *}, \mathrm{P}<0.01\right)$. The experimental data are presented as mean \pm standard deviation $(\mathrm{SD})$.

\section{Results}

\section{Phycocyanin attenuates the hyper-proliferation of AGS cells induced post Hp infection}

To assess the effect of Hp infection of the proliferation of gastric epithelial cells (GECs), AGS cells were first co- 
cultured with $\mathrm{Hp}$ at the ratios of 1:20 and 1:50 for 24 and $48 \mathrm{~h}$, and their cell viability was measured using a CCK8 kit. The results showed that the Hp infection at an AGS cell/Hp ratio of 1:50 significantly induces an increase in the number of AGS cells as compared to that at an AGS cell/ Hp ratio of 1:20, in a time-independent manner (Figure $1 A$ ). Consequently, an AGS cell/Hp ratio of 1:50 was chosen for subsequent experiments.

Next, to determine the effect of phycocyanin pretreatment of the cell viability of GECs post Hp infection, the AGS cells were treated with $150 \mu \mathrm{M}$ phycocyanin for $24 \mathrm{~h}$, followed by exposure to Hp for $24 \mathrm{~h}$, and their cell viability was measured. The results revealed that the number of viable cells in the Phycocyanin (PC)+ Hp group was significantly lower than that in the Hp group $(\mathrm{P}<0.01)$ (Figure 1B). Moreover, there was no statistically significant difference between the viabilities of the cells belonging to the normal control (NC) and PC groups, indicating that phycocyanin does not affect the cell viability of AGS cells.

\section{Phycocyanin significantly affects the apoptosis and cell cycle progression of Hp-infected AGS cells}

As phycocyanin was found to inhibit the growth of $\mathrm{Hp}$ infected AGS cells, we further studied its effects on apoptosis in these cells by using Annexin V/PI double staining to detect cell surface phosphatidylserine, and determined the percentage of Annexin $\mathrm{V}$-positive apoptotic cells of the total cells. Our results revealed that in comparison to the $\mathrm{NC}$ groups, $\mathrm{Hp}$ did not induce apoptosis of AGS cells upon infection at a MOI of 1:20 and 1:50 for $48 \mathrm{~h}$ (Figure 1C).

To elucidate the mechanism of phycocyanin-induced growth inhibition in Hp-infected AGS cells, the effects of phycocyanin on cell cycle progression were determined by flow cytometry. The results showed that $\mathrm{Hp}$ infection caused significant changes in the cell cycle distribution of AGS cells (Figure 1D). More specifically, the proportion of cells in the G0G1 and S phases was found to be significantly lower and higher, respectively, in the Hp group than in the $\mathrm{NC}$ group $(\mathrm{P}<0.05)$. Moreover, the proportion of $\mathrm{S}$ phase cells was markedly lower in the $\mathrm{PC}+\mathrm{Hp}$ group than in the Hp group $(\mathrm{P}<0.05)$. Additionally, the proportion of $\mathrm{S}$ phase cells was not notably different in the NC group compared to the PC group, suggesting that the action of phycocyanin alone did not affect cell cycle progression of AGS cells. Overall, these results indicate that phycocyanin inhibited the proliferative effect of $\mathrm{Hp}$ infection in AGS cells.

\section{Phycocyanin regulates cell cycle progression by decreasing the expression of $c$-myc and CyclinD1 proteins associated with cell cycle regulation in AGS cells}

To investigate the effect of phycocyanin on the progression of the cell cycle in GECs, the expression of cell cycleassociated genes such as $c-m y c$ and $C y c l i n D 1$ was determined at both the transcript and protein levels. The messenger RNA (mRNA)and protein expression levels of c-myc and CyclinD1 were accordingly measured by RT-qPCR and western blot analysis, respectively. The results showed that in the Hp group, the mRNA expression of $c-m y c$ and CyclinD1 was markedly increased in the AGS cells, as compared to that in the $\mathrm{NC}$ group $(\mathrm{P}<0.01)$ (Figure $2 A)$. Moreover, no statistically significant difference was identified between the NC and PC groups, while the expression of c-myc and CyclinD1 transcripts was found to be significantly reduced in the $\mathrm{PC}+\mathrm{Hp}$ group compared to the Hp group $(\mathrm{P}<0.05)$. Furthermore, the protein expression of c-myc and CyclinD1 was also determined to be significantly elevated in the $\mathrm{Hp}$ group ( $\mathrm{Hp}$ infected with a MOI 1:50 for $12 \mathrm{~h}$ ) compared with the NC group $(\mathrm{P}<0.01)$ (Figure $2 B$ ). In contrast, phycocyanin pre-treatment of $\mathrm{Hp}$-infected cells $(\mathrm{PC}+\mathrm{Hp}$ group) notably reduced the Hp infection-induced increased expression of c-myc and CyclinD1 (Hp group) $(\mathrm{P}<0.01$, Figure $2 B)$.

\section{Phycocyanin pre-treatment alters the transcriptome of $\mathrm{Hp}$ - infected AGS cells}

Our study revealed that phycocyanin inhibited the Hpinduced cellular hyper-proliferation in AGS cells. To gain deeper insight into the mechanism of action of phycocyanin, we performed RNA sequencing (RNA-seq) analysis of $\mathrm{Hp}$-infected AGS cells subjected to a prior phycocyanin intervention. Comparisons of the transcriptomes were made between the following groups: (I) AGS cells not infected with $\mathrm{Hp}$ and not using phycocyanin action (NC) and AGS cells infected with Hp only (Hp); (II) AGS cells not infected with $\mathrm{Hp}$ and not using phycocyanin action (NC) and AGS cells infected with phycocyanin action only (PC); and (III) AGS cells infected with Hp only (Hp) and phycocyanin treated and infected with $\mathrm{Hp}$ cells $(\mathrm{PC}+\mathrm{Hp})$. The DEGs were strictly screened between groups using $\mathrm{P}<0.05$, and $\log 2 \mathrm{FC}$ fold change of $\leq-1$ (down-regulation) or $\geq 1$ (up-regulation). Transcriptome data analyses revealed a total of 1,055 DEGs in the four experimental systems (Figure 3A). More specifically, 248 genes were found to 

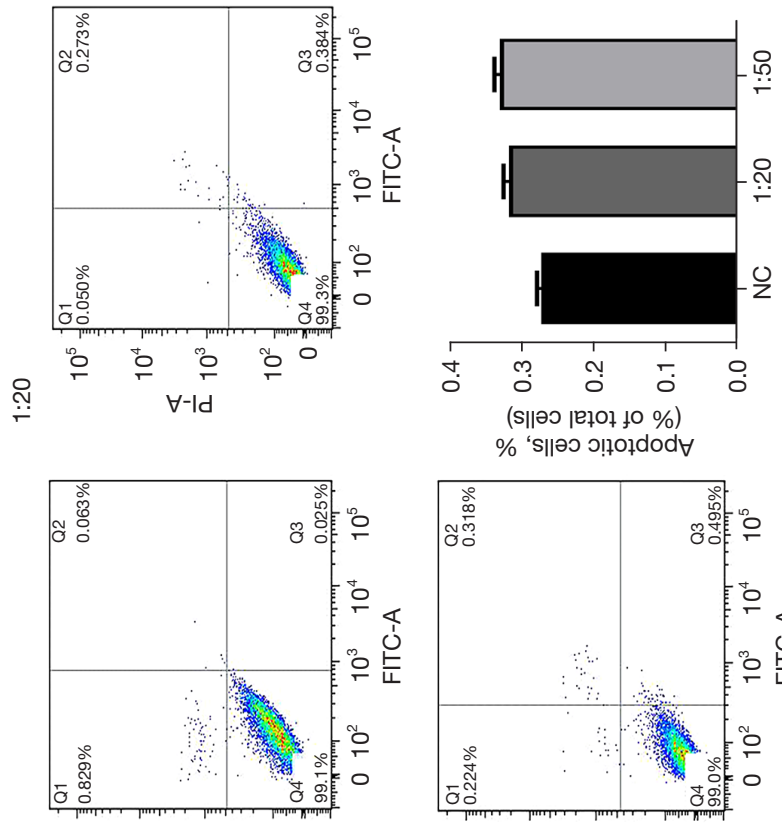

z

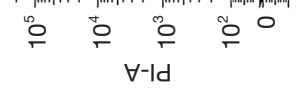

U
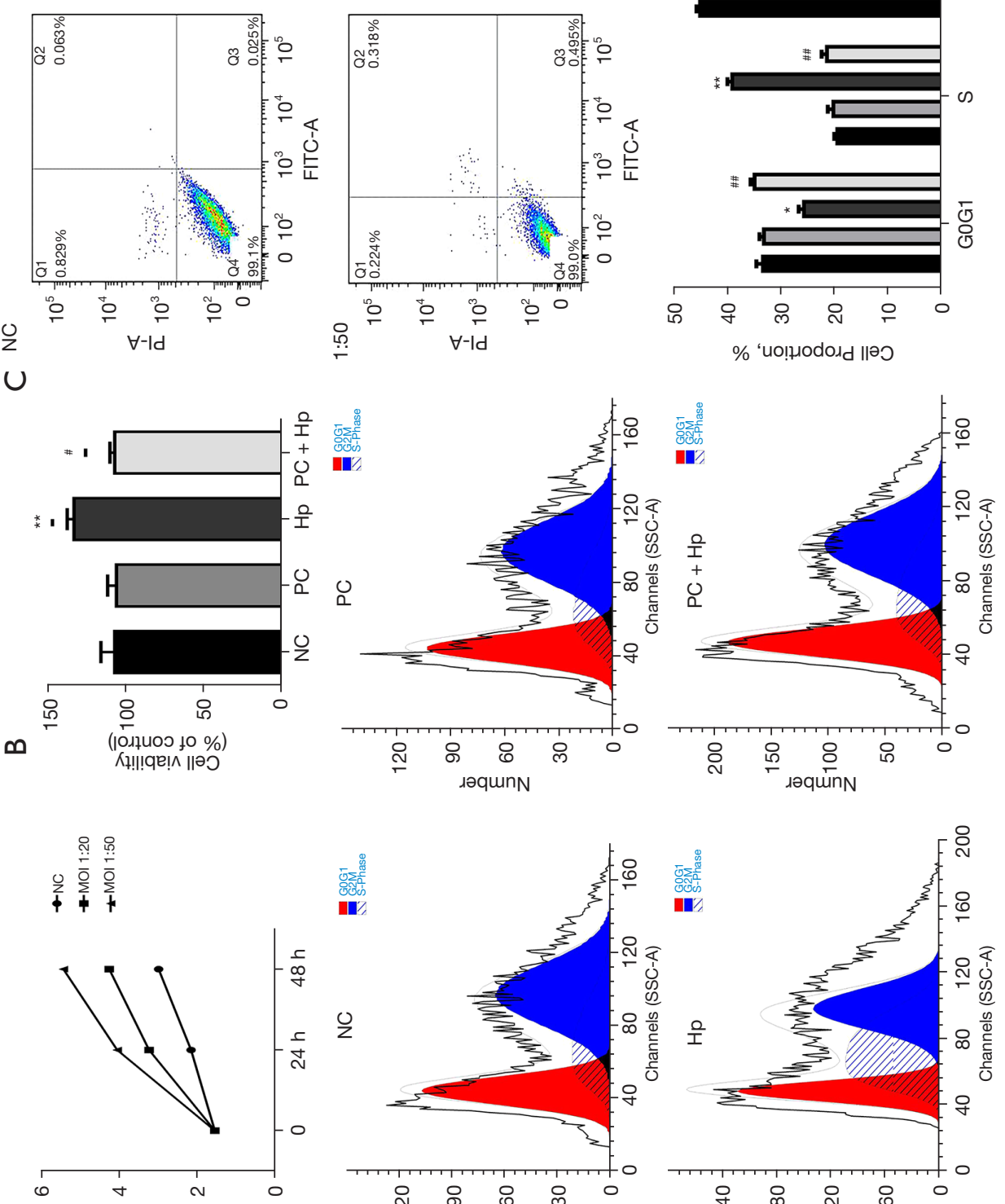

$\varangle$

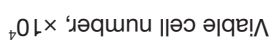

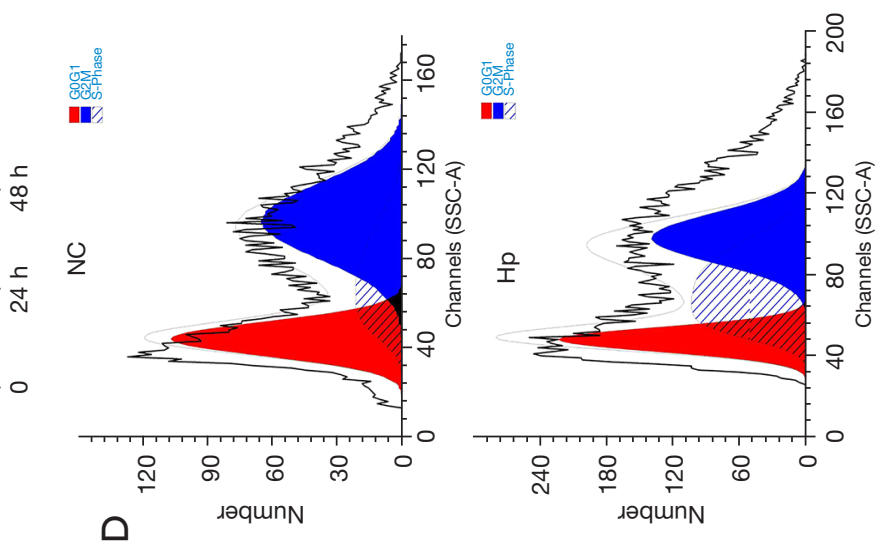

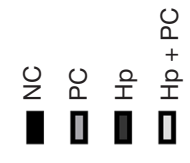
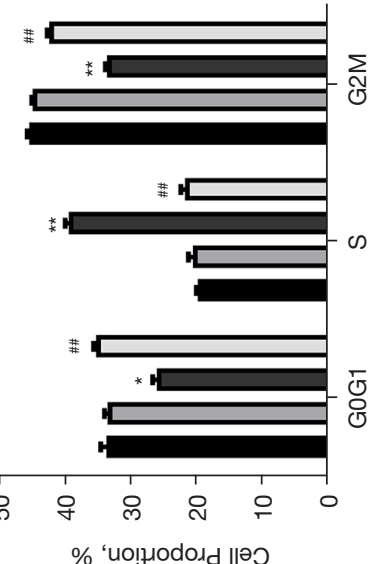

$\%$ 'uo!prododd IIə⿹

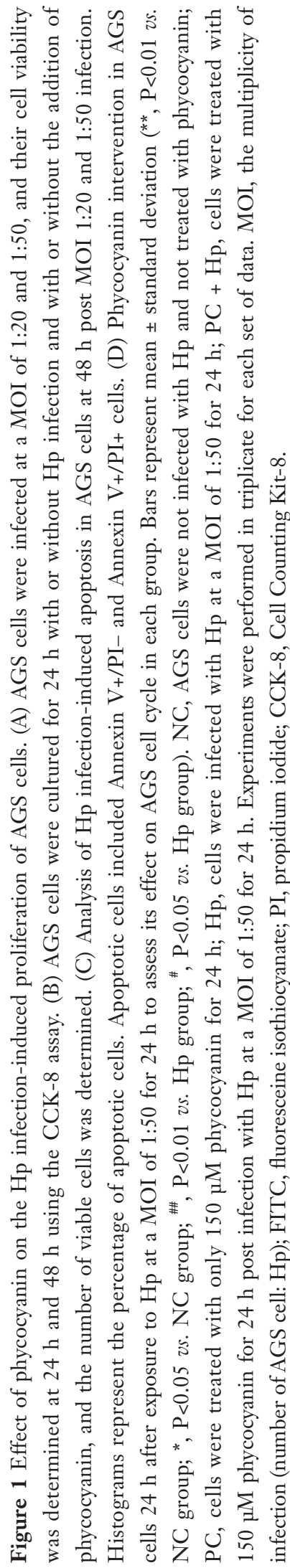



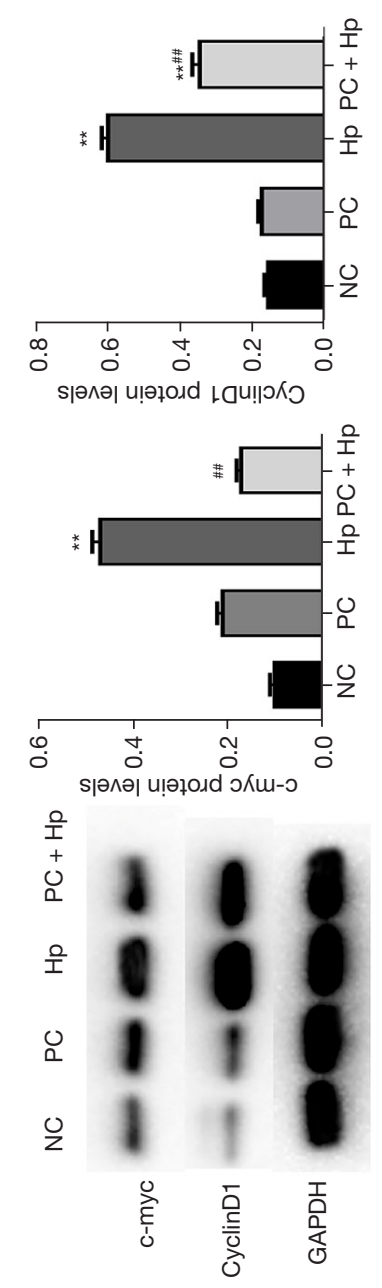

$\infty$
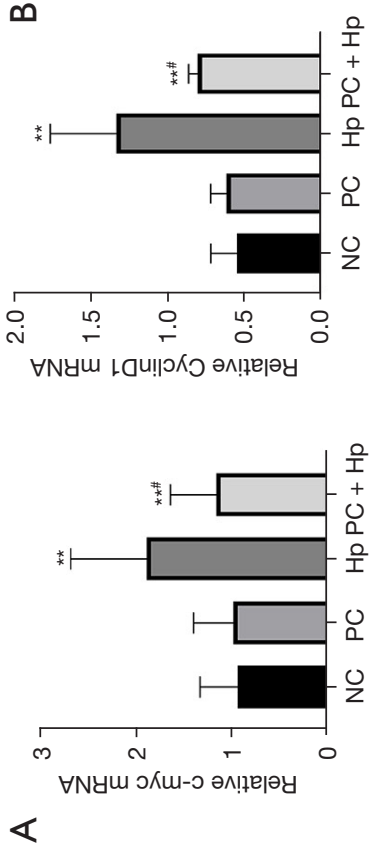

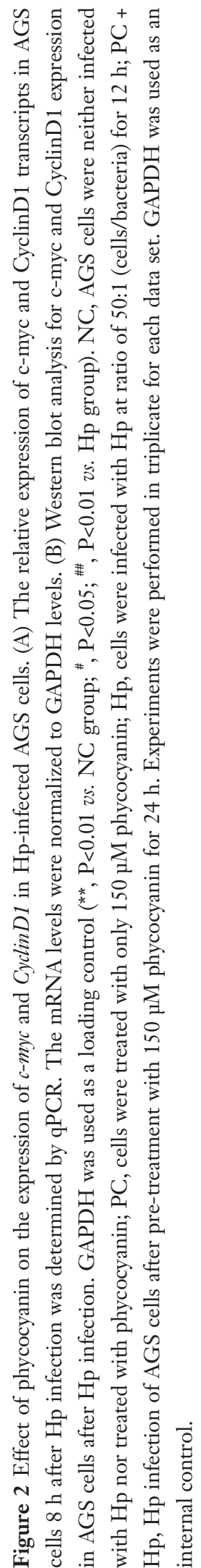

be upregulated (HP up) while 51 genes were found to be downregulated (Hp down) during Hp infection of AGS cells (Figure 3B). Furthermore, the intervention of AGS cells with phycocyanin before $\mathrm{Hp}$ infection resulted in the upregulation of 235 genes (PC $+\mathrm{Hp}$ up), 16 of which were suppressed by $\mathrm{Hp}$ infection, and downregulation of 468 genes ( $\mathrm{PC}+\mathrm{Hp}$ down), 165 of which were upregulated post Hp infection.

\section{Biological function and pathology analysis of DEGs in AGS cells during Hp infection post-phycocyanin intervention}

To determine the biological functions of DEGs in Hpinfected AGS cells pre-treated with phycocyanin, we performed GO enrichment analysis to annotate genes that were upregulated in the $\mathrm{Hp}$ group but not in the $\mathrm{PC}+\mathrm{Hp}$ group of cells. The 30 most significantly-enriched GO terms are shown in Figure 3C. Biological processes including protein tyrosine/threonine phosphatase cascade, regulation of protein phosphorylation, DNA-binding transcription factor activity, cell communication processes, cell proliferation processes, and signaling pathways such as cell migration/migration were upregulated after $\mathrm{Hp}$ infection, but to a lesser extent in cells treated with phycocyanin before infection. To elucidate the biological pathways regulated by DEGs, we performed an enrichment analysis of the KEGG pathways for these genes. Our analyses revealed that the mitogen-activated protein kinase (MAPK) signaling pathway had the most significant enrichment and contained the most DEGs (Figure 3D).

\section{Phycocyanin affects the expression of phosphorylated proteins in the MAPK signaling pathway in Hp-infected AGS cells}

Based on the transcriptome profiling results, the expression of DUPS2, GADD45A, FOSB, FOSL, and MAP3K4 in Hpinfected AGS cells after phycocyanin pre-treatment was verified by RT-qPCR. These genes, which are associated with the MAPK signaling pathway, were found to be upregulated upon $\mathrm{Hp}$ infection in transcriptome analysis and were significantly downregulated upon phycocyanin pre-treatment. Our RT-qPCR studies showed that the expression of DUPS2, GADD45A, FOSB, FOSL, and $M A P 3 K 4$ in the $\mathrm{PC}+\mathrm{Hp}$ group was significantly lower than that in the Hp group $(\mathrm{P}<0.01$, Figure $4 A)$. These results are consistent with the results of our RNA-Sequencing studies, which further corroborates our findings. 

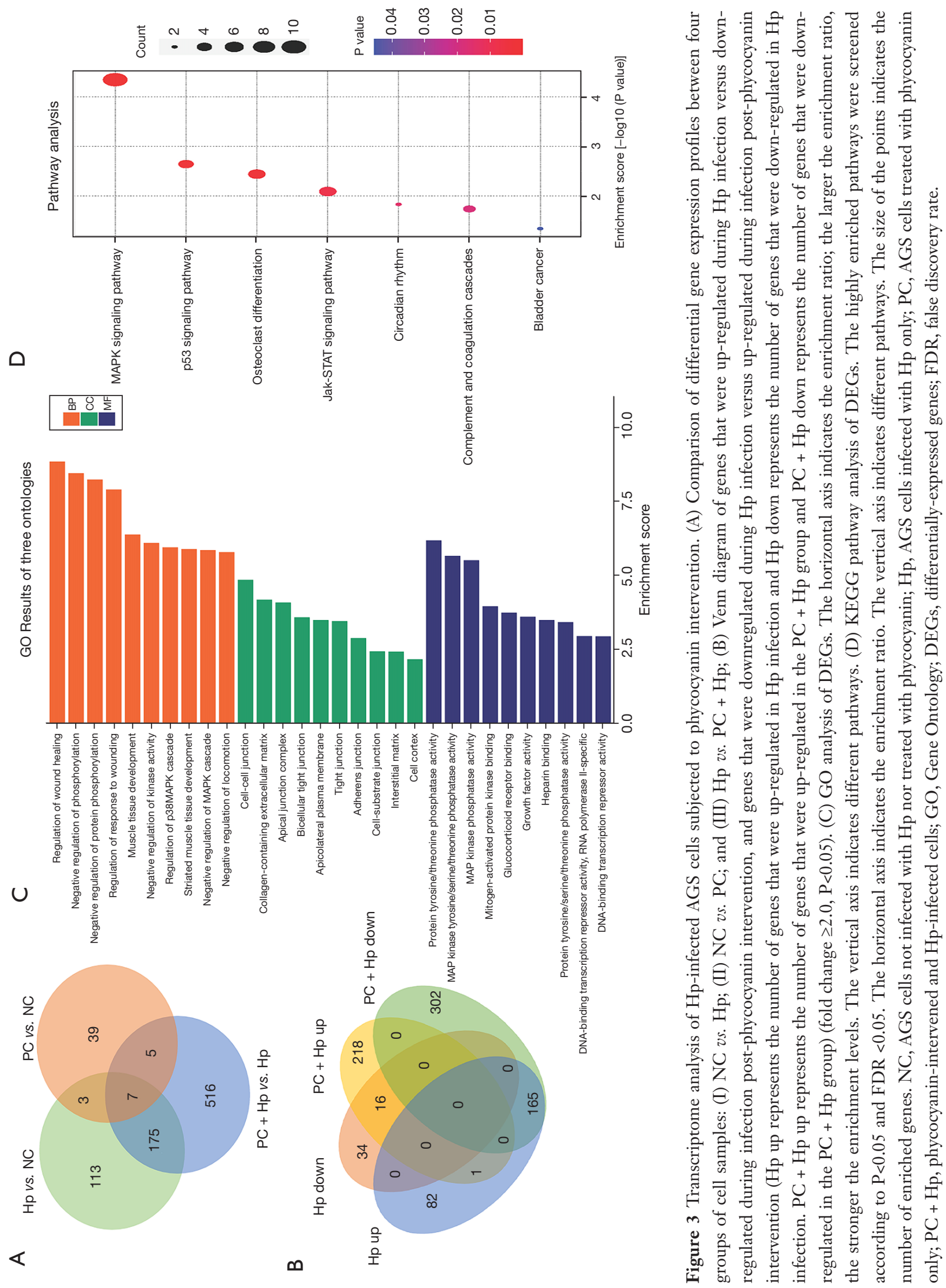

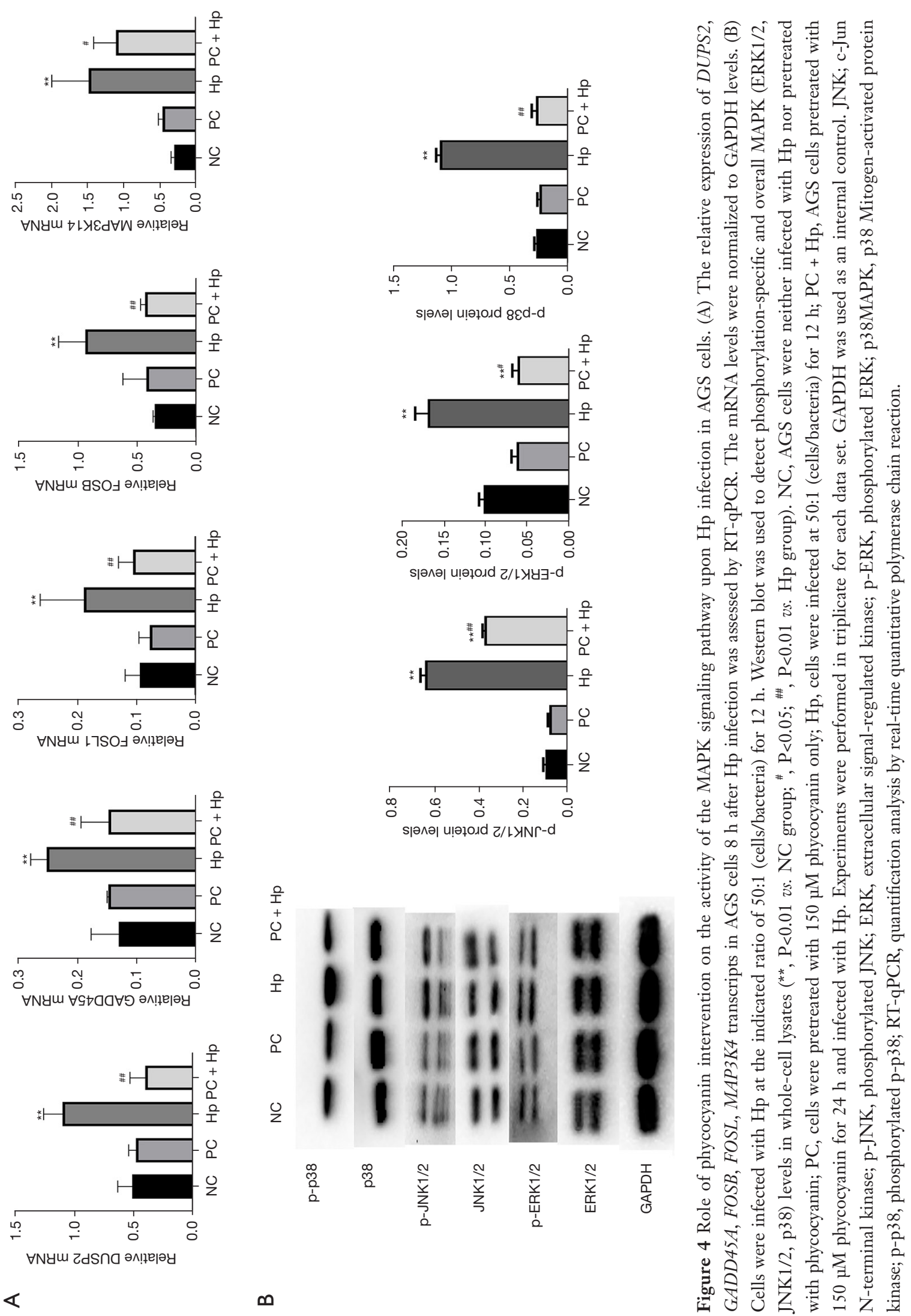
Subsequently, we examined the effect of pre-treatment with $150 \mu \mathrm{M}$ phycocyanin on MAPK signaling pathway activity in Hp-infected AGS cells. The results revealed that while the total protein levels of JNK, ERK, and p38 remained stable, their phosphorylation levels (phosphoJNK-Ser176/180, phospho-ERK-Ser32, and phospho-p38Ser536) were markedly higher in the Hp group than in the $\mathrm{NC}$ group $(\mathrm{P}<0.05)$, while the same was reduced in the $\mathrm{PC}+\mathrm{Hp}$ group as compared with the $\mathrm{Hp}$ group $(\mathrm{P}<0.05$, Figure $4 B)$. Interestingly, no significant differences were found in phosphorylation and total protein levels in the PC group compared to the NC group, indicating that the activity of the MAPK signaling pathway activated by Hp infection is inhibited by phycocyanin.

\section{Inbibition of the MAPK signaling patbway increases the c-myc and CyclinD1 expression in Hp-infected AGS cells subjected to phycocyanin intervention}

To confirm the involvement of MAPKs in the regulation of phycocyanin-induced inhibition of hyper-proliferation of Hp-infected AGS cells, $20 \mu \mathrm{M} \mathrm{SB} 203580$ (p38 inhibitor), $20 \mu M$ U1026 (ERK inhibitor), and $10 \mu M$ SP600125 (JNK inhibitor) were used to interfere with MAPK signaling in AGS cells for $1 \mathrm{~h}$. This was followed by treatment with $150 \mu M$ phycocyanin and detection of p38, ERK, and JNK signaling pathway-induced expression of c-myc and CyclinD1 in Hp-infected AGS cells. Our results revealed all three MAPK inhibitors significantly rescued the phycocyanin-induced downregulation of c-myc and CyclinD1 in Hp-infected AGS cells $(\mathrm{P}<0.05$, Figure $5 A)$. These results suggest that phycocyanin regulated the normalization of the cell cycle after $\mathrm{Hp}$ infection through the p38, ERK, and JNK signaling pathways.

\section{Phycocyanin inhibits increased ROS levels and suppresses $N F-\kappa B$ signaling patbway activity in $\mathrm{Hp}$-infected cells}

The balance of intracellular ROS is critical in determining cellular fate. In order to assess the effect of phycocyanin intervention on Hp-infected AGS cells, the levels of ROS were measured in phycocyanin treated Hp-infected AGS cells with the help of 2, 7-Dichlorodihydrofluorescein diacetate (DCFH-DA) probes. The results showed that compared to the NC group, the Hp group demonstrated markedly increased ROS accumulation. There was no statistically significant difference between the ROS level of the cells belonging to the NC and PC groups. Furthermore, the PC $+\mathrm{Hp}$ group exhibited reduced ROS levels as compared to the Hp group, indicating that phycocyanin specifically reduced the elevated ROS caused by $\mathrm{Hp}$ infection in AGS cells (Figure 5B).

To explore the regulatory role of phycocyanin on NF$\kappa \mathrm{B}$ in $\mathrm{Hp}$-infected AGS cells, we examined the protein expression of key players in the NF- $\mathrm{KB}$ signaling pathway. Phosphorylation of the Ser32 site of the IкB- $\alpha$ protein leads to ubiquitin-mediated proteasome-dependent IкB $\alpha$ degradation and subsequent p65 entry into the nucleus for activation (21). Our results showed that although the total amount of I $\kappa \mathrm{B} \alpha$ remained stable in the Hp group as compared to the NC group, its phosphorylation level was found to be decreased $(\mathrm{P}<0.05)$, leading to enhanced $\mathrm{p} 65$ entry into the nucleus (Figure $6 A, 6 B$ ), indicating activation of the NF- $\kappa \mathrm{B}$ signaling pathway. Furthermore, the PC + Hp group showed significantly higher levels of IкB $\alpha$ phosphorylation $(\mathrm{P}<0.05)$ and decreased $\mathrm{p} 65$ entry into the nucleus as compared with the Hp group, suggesting that $\mathrm{NF}-\kappa \mathrm{B}$ signaling activated by $\mathrm{Hp}$ infection was inhibited by phycocyanin.

\section{Discussions}

The interaction between Hp and GECs leads to the activation of multiple signaling cascades that induce hyper cell proliferation, which may lead to tumorigenesis (22). Existing literature reports that $\mathrm{Hp}$ promotes the proliferation of GECs at low concentrations, and promotes apoptosis at high concentrations (23). In this study, we used flow cytometry to demonstrate that Hp-infected cells at a cell/bacteria ratio of 1:50 significantly promote cell proliferation at $24 \mathrm{~h}$ post-infection (Figure $1 \mathrm{~A}$ ) and do not increase apoptosis of AGS cells at $48 \mathrm{~h}$ post-infection (Figure 1C). As a result, this ratio was used for modeling $\mathrm{Hp}$ infection in subsequent experimental studies.

Our results showed that the application of phycocyanin $(150 \mu \mathrm{M})$ protects GECs from hyper-proliferation caused by Hp infection (Figure $1 B$ ), and the effect of phycocyanin application alone did not induce toxicity in AGS cells. Furthermore, Hp infection was found to promote the conversion of AGS cells from the G0/G1 phase to the $S$ phase of the cell cycle, whereas the $S$ phase cells were reduced and the cell cycle returned to normal after preintervention with phycocyanin (Figure 1D). A deregulated cell cycle underlies the development of many tumors (24). The mammalian cell cycle is controlled by a group of proteins known as cyclins (25), and the transcription factor 
A
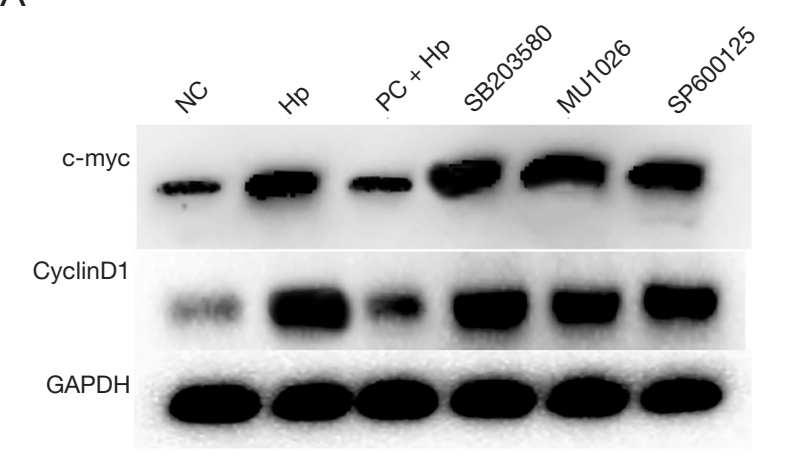

B
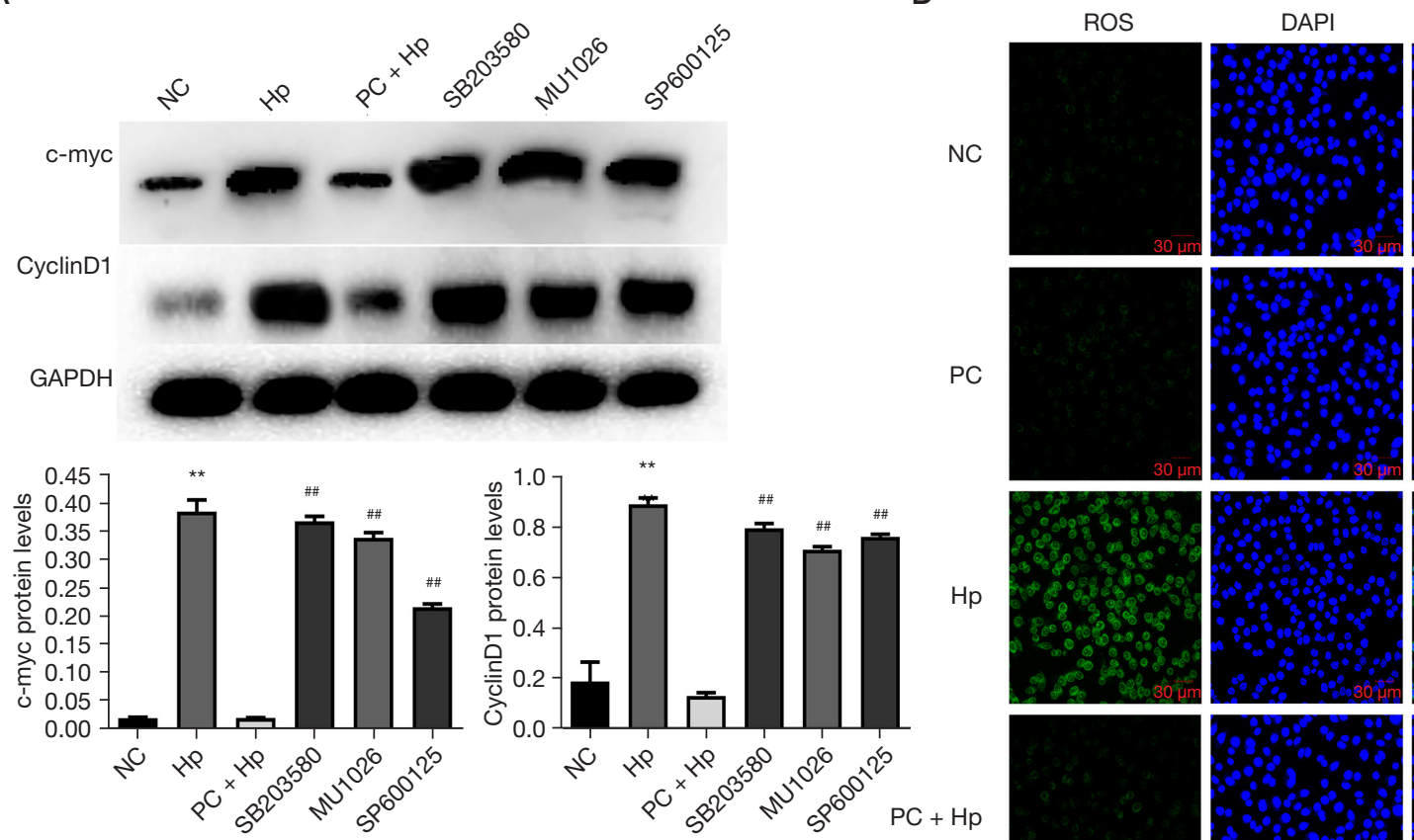

PC
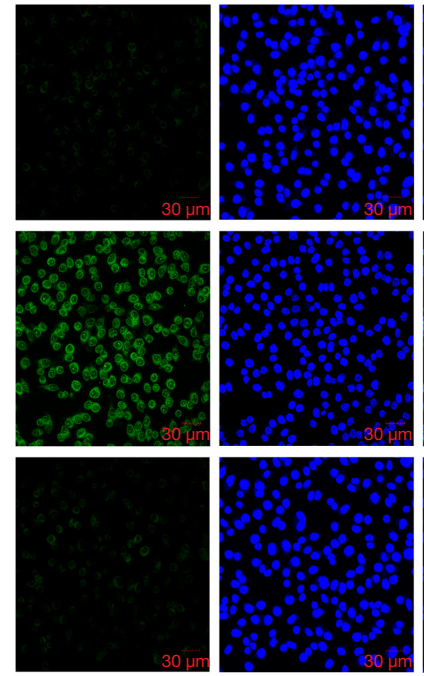

Merge
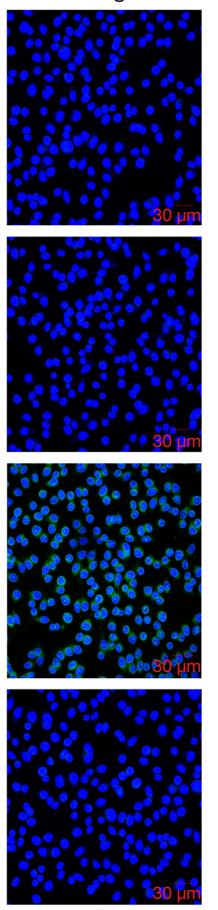

Figure 5 Effect of phycocyanin on the expression of c-myc and CyclinD1 and ROS levels in Hp-infected AGS cells. (A) Western blot analysis for c-myc and CyclinD1 expression in AGS cells after Hp infection. AGS cells were pre-incubated with SB203580 (p38 inhibitor), U1026 (ERK inhibitor), and SP600125 (JNK inhibitor) for $1 \mathrm{~h}$, followed by treatment with $150 \mu \mathrm{M}$ phycocyanin, and subsequently infected with Hp at 50:1 (cells/bacteria) for $12 \mathrm{~h}$. The cells were then assayed by western blotting to measure the levels of c-myc and CyclinD1. GAPDH was used as a loading control (**, $\mathrm{P}<0.01$ vs. NC group; ;, $\mathrm{P}<0.01$ vs. $\mathrm{PC}+\mathrm{Hp}$ group). (B) DCF fluorescence-based detection of intracellular ROS levels post-intervention with $150 \mu \mathrm{M}$ phycocyanin for $24 \mathrm{~h}$, followed by infection with $\mathrm{Hp}$ for $4 \mathrm{~h}$ (cell to Hp ratio of 1:50), scale bar $=30 \mu \mathrm{m}$. NC, AGS cells were neither infected with Hp nor treated with phycocyanin; PC, cells were treated with $150 \mu \mathrm{M}$ phycocyanin only; Hp, cells were infected with Hp at 50:1 (cells/bacteria) for 4 h; PC + Hp, AGS cells were infected with Hp post-24 h intervention with $150 \mu M$ phycocyanin. ROS, reactive oxygen species; DCF, Dichlorofluorescin; DAPI, 2-(4-Amidinophenyl)-6-indolecarbamidine dihydrochloride.

$c$-myc has been reported to induce the expression of the CyclinD1 gene (26). In this study, we demonstrated that the transcription and expression of $c-m y c$ and $C y c l i n D 1$ was increased after Hp infection of AGS cells (Figure 2). c-myc protein plays a key role in regulating the G1/S transition of the cell cycle, and its activation accelerates cell proliferation. CyclinD1 protein plays an important positive regulatory role in the $\mathrm{G} 1$ to $\mathrm{S}$ phase transition, and its overexpression leads to a shortened G1 phase and accelerated cell division (27). Intervention of cells with phycocyanin prior to $\mathrm{Hp}$ infection inhibits the increase in c-myc and CyclinD1 expression. Previous studies have reported that phycocyanin inhibits the cell cycle in esophageal cancer squamous cells (28), cervical cancer cells (29), and breast cancer cells (30) by decreasing the expression of cell cycle proteins D1, Cyclin dependent kinase (CDK)-2, and CDK-4.

Few studies have reported on the application of transcriptomic approaches to study the effect of phycocyanin in human cells. A transcriptomic analysis in ovarian cancer cells revealed that phycocyanin inhibits ovarian cancer cell proliferation by regulating the VEGF, p53, and neurotrophic factor pathways (31). In addition, phycocyanin exerts anti-proliferative effects on non-small cell lung cancer A549 cells by downregulating toll/interleukin 1 receptor domain-containing adaptor protein (TIRAP) NF$\kappa \mathrm{B}$ activity (32). To the best of our knowledge, there is no reported transcriptome analysis investigating the effect of phycocyanin on Hp-infected AGS cells. Consequently, we analyzed 165 differentially expressed genes whose expression was up-regulated after $\mathrm{Hp}$ infection, but down- 
A
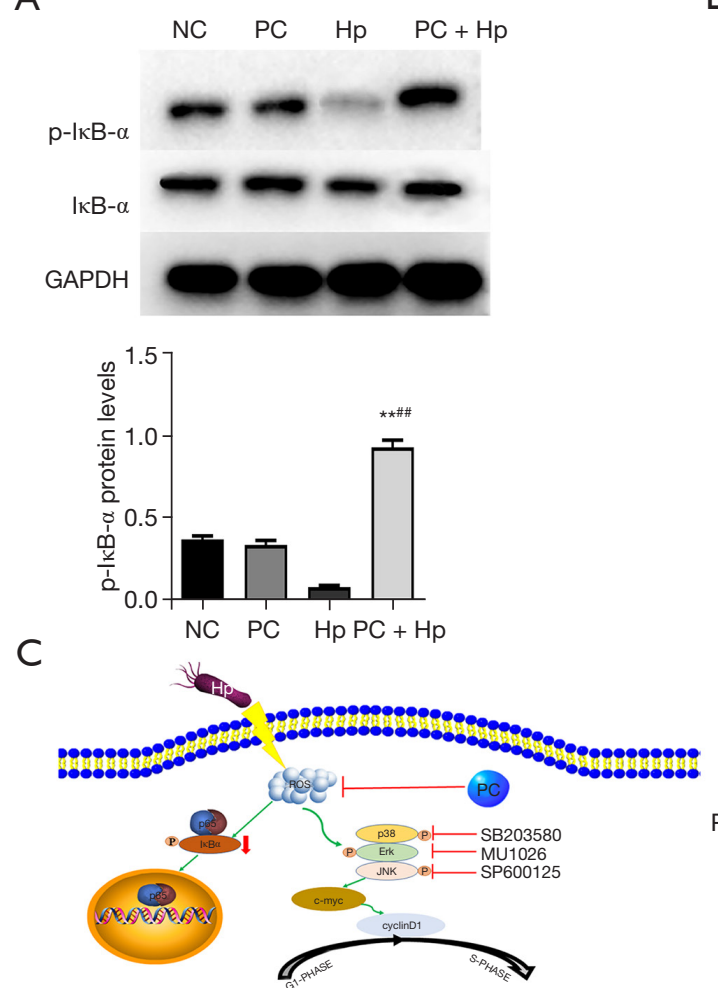

B

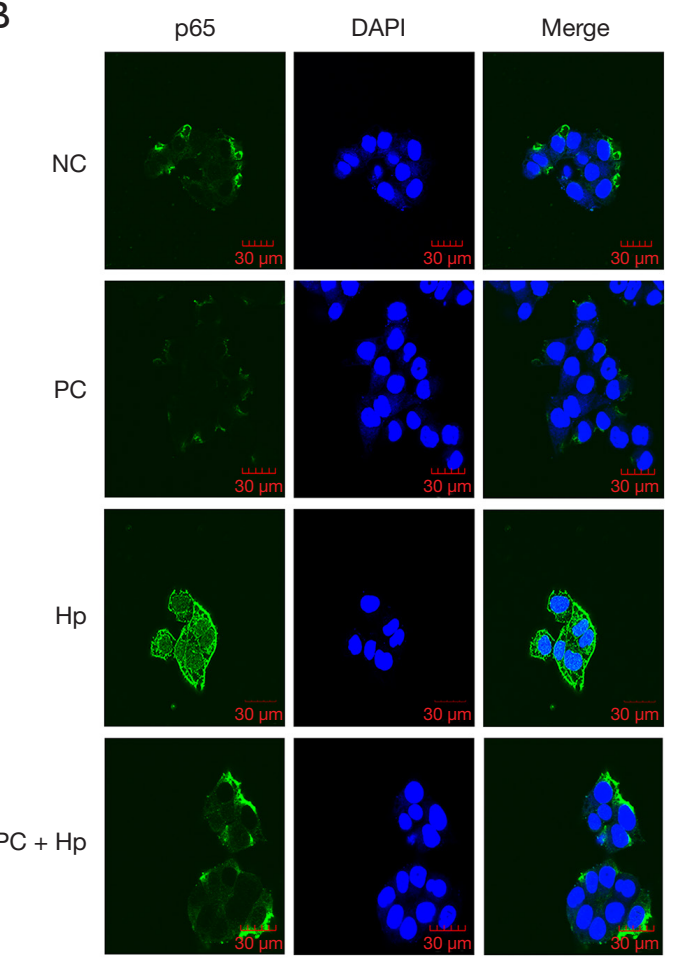

Figure 6 Effect of phycocyanin on NF- $\kappa B$ signaling pathway activation in Hp-infected AGS cells and Mechanism of action of phycocyanin in Hp infected cells. (A) Western blot assay of whole-cell lysates for the phosphorylation-specific and total form of IкB- $\alpha$ levels in $150 \mu M$ phycocyanin-pre-treated AGS cells 24 h post-Hp infection of cells at 50:1 (cells/bacteria) for $12 \mathrm{~h}$ (**, $\mathrm{P}<0.01 v s$. NC group; ${ }^{\# \#, ~} \mathrm{P}<0.01$ vs. Hp group). (B) Immunofluorescence-based detection of NF-kB p 65 in AGS cells post intervention with $150 \mu \mathrm{M}$ phycocyanin for $24 \mathrm{~h}$ followed by infection with $\mathrm{Hp}$ for $12 \mathrm{~h}$ (cell to Hp ratio of 1:50). Cells were stained with mouse anti-p65 antibody and 488-labeled goat anti-mouse IgG antibody. The left panel shows p65 immunocytochemical staining (green), and DAPI was used to stain the nuclei (blue), scale bar $=30 \mu \mathrm{m}$. NC, AGS cells were neither infected with Hp nor treated with phycocyanin; PC, cells were treated with $150 \mu \mathrm{M}$ phycocyanin only; Hp, cells were infected with $\mathrm{Hp}$ at 50:1 (cells/bacteria) for 4 h; PC + Hp, AGS cells were infected with Hp post-24 h intervention with $150 \mu \mathrm{M}$ phycocyanin. (C) In Hp-infected AGS cells, phycocyanin weakens the phosphorylation of MAPK family proteins and inhibits the transition of cells from G1 phase to $\mathrm{S}$ phase of the cell cycle by scavenging ROS and reducing the expression of CyclinD1, so as to inhibit the excessive

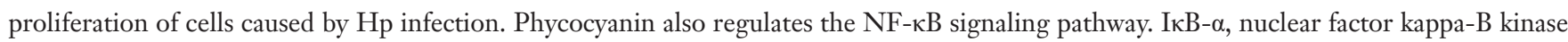

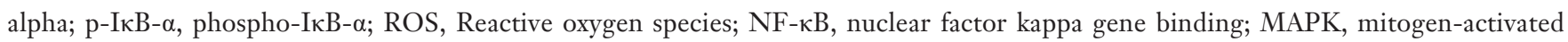
protein kinase.

regulated after phycocyanin intervention (Figure 3B). These genes were subsequently found to be involved in different anti-inflammatory and anti-tumor functional pathways, with the most enriched differential genes, as well as the most significant pathway, the MAPK signaling pathway (Figure 3D). Accordingly, we hypothesized that the MAPK pathway plays a key role in determining the therapeutic efficacy of phycocyanin against Hp infection in GECs.

Mammalian MAPKs include c-Jun NH2-terminal kinase (JNK), p38 MAPK, and ERKs. These enzymes are serine-threonine protein kinases that regulate a variety of cellular activities, including proliferation, differentiation, apoptosis, survival, inflammation, and innate immunity $(33,34)$. The previous study has reported that $\mathrm{Hp}$ infection of cells promotes phosphorylation of ERK, p38, and JNK kinases, which in turn promotes c-myc and CyclinD1 expression (35). This ultimately leads to increased proliferation, growth, migration, and invasiveness of GECs $(34,36)$. In the present study, phycocyanin was found to inhibit $\mathrm{Hp}$ infection-induced ERK1/2 phosphorylation, 
JNK1/2 phosphorylation, and p38 phosphorylation, indicating that phycocyanin can regulate the MAPK signaling pathway in response to Hp infection (Figure 4B). We also found that the addition of the ERK inhibitor U1026, p38 inhibitor SB203580, and JNK inhibitor SB600125 significantly attenuated the inhibition of c-myc and CyclinD1 protein expression induced by phycocyanin intervention (Figure 5A). These findings thus suggest that phycocyanin may regulate the alterations in the cell cycle of GECs in response Hp infection by regulating the activation of the MAPK pathway. Phycocyanin has been documented to regulate the MAPK signaling pathway in a variety of tumor cells as well as tyrosinase expression by inhibiting phosphorylation of ERK and p38 in melanoma cells (37), and activating the p38 and JNK pathways for anti-cancer activity in breast and pancreatic cancer cells $(30,38)$.

$\mathrm{Hp}$ infection has been reported to contribute to excessive cellular production of ROS by increasing nicotinamide adenosine dinucleotide phosphate (NADPH) oxidase activity. ROS is an important signaling molecule that is involved in the proliferation and invasion of cancer cells by activating regulatory MAPK in a variety of cells $(39,40)$. Numerous studies have reported that it is an important signaling molecule that activates regulatory MAPK in a variety of cells and is involved in cancer cell proliferation and invasion. Moreover, its inhibition can reduce MAPK activation (41-45). In our study, we found that cellular ROS levels were elevated and the MAPK signaling pathway was activated upon $\mathrm{Hp}$ infection, and that pre-treatment with phycocyanin reverses this effect (Figure 5B). These findings are also consistent with previous reports that suggested the ROS-lowering effect of phycocyanin in pancreatic $\beta$ cells and osteoblasts $(15,16)$. Consequently, we can reasonably attribute the phycocyanin-induced inhibition of MAPK activation to the antioxidant activity of phycocyanin.

A considerable body of evidence has suggested that phycocyanin has no fixed target of action in exerting antiinflammatory and anti-tumor processes, but rather has a regulatory role in a variety of signaling pathways. Hp is also involved in the development of gastric inflammation and tumorigenesis in GECs by producing excessive ROS, leading to the degradation of $I \kappa \mathrm{B} \alpha$ and activation of $\mathrm{NF}-\kappa \mathrm{B}$, promoting cell proliferation and DNA damage $(6,46,47)$. These reports suggest that phycocyanin plays a regulatory role in the NF- $\mathrm{NB}$ pathway to inhibit tumor cell proliferation in hepatocellular carcinoma and lung cancer cells $(38,48)$. In this study, we observed that phosphorylated
I $\kappa \mathrm{B} \alpha$ was decreased upon Hp infection (Figure $6 A$ ), and active NF- $\kappa \mathrm{B}$ levels were elevated (Figure $6 B$ ). In addition, pre-treatment with phycocyanin results in increased levels of phosphorylated I $\kappa \mathrm{B} \alpha$ and decreased NF- $\mathrm{NB}$ entry into the nucleus. MAPK inhibitors were found to be effective in inhibiting $\mathrm{Hp}$-infection-induced NF- $\kappa \mathrm{B}$ activation in a previous investigation (49). As a result, it has been suggested that in Hp-infected AGS cells, NF- $\kappa \mathrm{B}$ activation may be a downstream pathway of the ERK and/or p38 signaling pathways. Our current experimental findings also support that phycocyanin has a regulatory effect on the MAPK and NF- $\mathrm{\kappa B}$ signaling pathways in Hp-infected AGS cells. However, the mechanism of interaction between the two is unclear (Figure 6C). To our knowledge, few studies have reported the role of phycocyanin in Hp infection, which lays the theoretical foundation for the application of marine functional foods in the treatment of $\mathrm{Hp}$ infection.

\section{Conclusions}

In this study, we demonstrated that the natural functional food colorant, phycocyanin, has an inhibitory effect on $\mathrm{Hp}$-induced cellular hyper proliferation of GECs. The mechanism of action of phycocyanin is associated with its antioxidant properties, which play a key role in the pathological response caused by $\mathrm{Hp}$ infection through the ROS/MAPK signaling pathway. Although the exact mechanism needs to be further investigated, the present findings provide evidence to further explore the anti-Hp infection mechanisms of phycocyanin.

\section{Acknowledgments}

Funding: This work was supported by grants from the National Natural Science Foundation of China (No. 81860353), the Cultivation Project of the National Natural Science Foundation of Guizhou Medical University (No. 20NSP005), and the Colleges and Universities Students' Innovation Training Project (No. 202010660001).

\section{Footnote}

Reporting Checklist: The authors have completed the MDAR reporting checklist. Available at https://atm.amegroups. com/article/view/10.21037/atm-21-7045/rc

Data Sharing Statement: Available at https://atm.amegroups. com/article/view/10.21037/atm-21-7045/dss 
Conflicts of Interest: All authors have completed the ICMJE uniform disclosure form (available at https://atm. amegroups.com/article/view/10.21037/atm-21-7045/coif). The authors have no conflicts of interest to declare.

Ethical Statement: The authors are accountable for all aspects of the work in ensuring that questions related to the accuracy or integrity of any part of the work are appropriately investigated and resolved.

Open Access Statement: This is an Open Access article distributed in accordance with the Creative Commons Attribution-NonCommercial-NoDerivs 4.0 International License (CC BY-NC-ND 4.0), which permits the noncommercial replication and distribution of the article with the strict proviso that no changes or edits are made and the original work is properly cited (including links to both the formal publication through the relevant DOI and the license). See: https://creativecommons.org/licenses/by-nc-nd/4.0/.

\section{References}

1. Hooi JKY, Lai WY, Ng WK, et al. Global Prevalence of Helicobacter pylori Infection: Systematic Review and Meta-Analysis. Gastroenterology 2017;153:420-9.

2. Xie C, Yi J, Lu J, et al. N-Acetylcysteine Reduces ROSMediated Oxidative DNA Damage and PI3K/Akt Pathway Activation Induced by Helicobacter pylori Infection. Oxid Med Cell Longev 2018;2018:1874985.

3. Díaz P, Valenzuela Valderrama M, Bravo J, et al. Helicobacter pylori and Gastric Cancer: Adaptive Cellular Mechanisms Involved in Disease Progression. Front Microbiol 2018;9:5.

4. Butcher LD, den Hartog G, Ernst PB, et al. Oxidative Stress Resulting From Helicobacter pylori Infection Contributes to Gastric Carcinogenesis. Cell Mol Gastroenterol Hepatol 2017;3:316-22.

5. Li X, Liu S, Luo J, et al. Helicobacter pylori induces IL$1 \beta$ and IL-18 production in human monocytic cell line through activation of NLRP3 inflammasome via ROS signaling pathway. Pathog Dis 2015;73:ftu024.

6. Gobert AP, Wilson KT. Polyamine- and NADPHdependent generation of ROS during Helicobacter pylori infection: A blessing in disguise. Free Radic Biol Med 2017;105:16-27.

7. Liu Z, Ren Z, Zhang J, et al. Role of ROS and Nutritional Antioxidants in Human Diseases. Front Physiol 2018;9:477.
8. Snezhkina AV, Kudryavtseva AV, Kardymon OL, et al. ROS Generation and Antioxidant Defense Systems in Normal and Malignant Cells. Oxid Med Cell Longev 2019;2019:6175804.

9. Serafini M, Bellocco R, Wolk A, et al. Total antioxidant potential of fruit and vegetables and risk of gastric cancer. Gastroenterology 2002;123:985-91.

10. Ajaikumar KB, Asheef $\mathrm{M}$, Babu BH, et al. The inhibition of gastric mucosal injury by Punicagranatum $\mathrm{L}$. (pomegranate) methanolic extract. J Ethnopharmacol 2005;96:171-6.

11. Yu P, Wu Y, Wang G, et al. Purification and bioactivities of phycocyanin. Crit Rev Food Sci Nutr 2017;57:3840-9.

12. Safaei M, Maleki H, Soleimanpour H, et al. Development of a novel method for the purification of C-phycocyanin pigment from a local cyanobacterial strain Limnothrix sp. NS01 and evaluation of its anticancer properties. Sci Rep 2019;9:9474.

13. Yang P, Li B, Yin QF, et al. Carboxymethyl chitosan nanoparticles coupled with CD59-specific ligand peptide for targeted delivery of C-phycocyanin to HeLa cells. Tumour Biol 2017;39:1010428317692267.

14. Hao S, Li S, Wang J, et al. Phycocyanin Exerts AntiProliferative Effects through Down-Regulating TIRAP/ NF- $\kappa B$ Activity in Human Non-Small Cell Lung Cancer Cells. Cells 2019;8:588.

15. AlQranei MS, Aljohani H, Majumdar S, et al. C-phycocyanin attenuates RANKL-induced osteoclastogenesis and bone resorption in vitro through inhibiting ROS levels, NFATc1 and NF-אB activation. Sci Rep 2020;10:2513.

16. Liu C, Fu Y, Li CE, et al. Phycocyanin-Functionalized Selenium Nanoparticles Reverse Palmitic Acid-Induced Pancreatic $\beta$ Cell Apoptosis by Enhancing Cellular Uptake and Blocking Reactive Oxygen Species (ROS)Mediated Mitochondria Dysfunction. J Agric Food Chem 2017;65:4405-13.

17. Bhat VB, Madyastha KM. C-phycocyanin: a potent peroxyl radical scavenger in vivo and in vitro. Biochem Biophys Res Commun 2000;275:20-5.

18. Riss J, Décordé K, Sutra T, et al. Phycobiliprotein C-phycocyanin from Spirulina platensis is powerfully responsible for reducing oxidative stress and NADPH oxidase expression induced by an atherogenic diet in hamsters. J Agric Food Chem 2007;55:7962-7.

19. Zhu C, Ling Q, Cai Z, et al. Selenium-Containing Phycocyanin from Se-Enriched Spirulina platensis Reduces Inflammation in Dextran Sulfate Sodium-Induced 
Colitis by Inhibiting NF- $\mathrm{B}$ Activation. J Agric Food Chem 2016;64:5060-70.

20. Zhang H, Chen T, Jiang J, et al. Selenium-containing allophycocyanin purified from selenium-enriched Spirulina platensis attenuates AAPH-induced oxidative stress in human erythrocytes through inhibition of ROS generation. J Agric Food Chem 2011;59:8683-90.

21. Yamamoto Y, Gaynor RB. IkappaB kinases: key regulators of the NF-kappaB pathway. Trends Biochem Sci 2004;29:72-9.

22. Brenes F, Ruiz B, Correa P, et al. Helicobacter pylori causes hyperproliferation of the gastric epithelium: preand post-eradication indices of proliferating cell nuclear antigen. Am J Gastroenterol 1993;88:1870-5.

23. Hirabayashi K, Fujimori T, Sakuma K, et al. Effect of Helicobacter pylori eradication from patients with gastritis evaluated by the pathological grading and cell proliferation related factors. Nihon Rinsho 1999;57:179-84.

24. Ristic B, Bhutia YD, Ganapathy V. Cell-surface G-proteincoupled receptors for tumor-associated metabolites: A direct link to mitochondrial dysfunction in cancer. Biochim Biophys Acta Rev Cancer 2017;1868:246-57.

25. Peyressatre M, Prével C, Pellerano M, et al. Targeting cyclin-dependent kinases in human cancers: from small molecules to Peptide inhibitors. Cancers (Basel) 2015;7:179-237.

26. Lemaitre JM, Buckle RS, Méchali M. c-Myc in the control of cell proliferation and embryonic development. Adv Cancer Res 1996;70:95-144.

27. Liu L, Zhao Y, Fan G, et al. Helicobacter pylori infection enhances heparanase leading to cell proliferation via mitogen-activated protein kinase signalling in human gastric cancer cells. Mol Med Rep 2018;18:5733-41.

28. Zhang X, Fan T, Li S, et al. C-Phycocyanin elicited antitumor efficacy via cell-cycle arrest, apoptosis induction, and invasion inhibition in esophageal squamous cell carcinoma. J Recept Signal Transduct Res 2019;39:114-21.

29. Ji H, Liu G, Han J, et al. C-phycocyanin inhibits epithelial-to-mesenchymal transition in Caski cells. Cancer Cell Int 2020;20:292.

30. Jiang L, Wang Y, Liu G, et al. C-Phycocyanin exerts anticancer effects via the MAPK signaling pathway in MDAMB-231 cells. Cancer Cell Int 2018;18:12.

31. Ying J, Wang J, Ji H, et al. Transcriptome analysis of phycocyanin inhibitory effects on SKOV-3 cell proliferation. Gene 2016;585:58-64.

32. Hao S, Li S, Wang J, et al. Transcriptome Analysis of Phycocyanin-Mediated Inhibitory Functions on Non-
Small Cell Lung Cancer A549 Cell Growth. Mar Drugs 2018;16:511.

33. Cargnello M, Roux PP. Activation and function of the MAPKs and their substrates, the MAPK-activated protein kinases. Microbiol Mol Biol Rev 2011;75:50-83.

34. Sun Y, Liu WZ, Liu T, et al. Signaling pathway of MAPK/ ERK in cell proliferation, differentiation, migration, senescence and apoptosis. J Recept Signal Transduct Res 2015;35:600-4.

35. Allison CC, Kufer TA, Kremmer E, et al. Helicobacter pylori induces MAPK phosphorylation and AP-1 activation via a NOD1-dependent mechanism. J Immunol 2009;183:8099-109.

36. Jang SH, Cho S, Lee ES, et al. The phenyl-thiophenyl propenone RK-I-123 reduces the levels of reactive oxygen species and suppresses the activation of $\mathrm{NF}-\kappa \mathrm{B}$ and $\mathrm{AP}-1$ and IL-8 expression in Helicobacter pylori-infected gastric epithelial AGS cells. Inflamm Res 2013;62:689-96.

37. Wu LC, Lin YY, Yang SY, et al. Antimelanogenic effect of c-phycocyanin through modulation of tyrosinase expression by upregulation of ERK and downregulation of p38 MAPK signaling pathways. J Biomed Sci 2011;18:74.

38. Liao G, Gao B, Gao Y, et al. Phycocyanin Inhibits Tumorigenic Potential of Pancreatic Cancer Cells: Role of Apoptosis and Autophagy. Sci Rep 2016;6:34564.

39. Zhang Q, Han Q, Yang Z, et al. G6PD facilitates clear cell renal cell carcinoma invasion by enhancing MMP2 expression through ROS-MAPK axis pathway. Int J Oncol 2020;57:197-212.

40. Li Y, Chen F, Chen J, et al. Disulfiram/Copper Induces Antitumor Activity against Both Nasopharyngeal Cancer Cells and Cancer-Associated Fibroblasts through ROS/ MAPK and Ferroptosis Pathways. Cancers (Basel) 2020;12:138.

41. Liu C, Hao K, Liu Z, et al. Epigallocatechin gallate (EGCG) attenuates staphylococcal alpha-hemolysin (Hla)-induced NLRP3 inflammasome activation via ROS-MAPK pathways and EGCG-Hla interactions. Int Immunopharmacol 2021;100:108170.

42. Bi C, Zhang X, Chen Y, et al. MAGT1 is required for HeLa cell proliferation through regulating p21 expression, S-phase progress, and ERK/p38 MAPK MYC axis. Cell Cycle 2021;20:2233-47.

43. Fontana F, Marzagalli M, Raimondi M, et al. $\delta$-Tocotrienol sensitizes and re-sensitizes ovarian cancer cells to cisplatin via induction of G1 phase cell cycle arrest and ROS/ MAPK-mediated apoptosis. Cell Prolif 2021;54:e13111.

44. Zhang Q, Han Q, Yang Z, et al. G6PD facilitates clear 
cell renal cell carcinoma invasion by enhancing MMP2 expression through ROS-MAPK axis pathway. Int J Oncol 2020;57:197-212.

45. Fu D, Wu D, Cheng W, et al. Costunolide Induces Autophagy and Apoptosis by Activating ROS/MAPK Signaling Pathways in Renal Cell Carcinoma. Front Oncol 2020;10:582273.

46. He Y, Wang C, Zhang X, et al. Sustained Exposure to Helicobacter pylori Lysate Inhibits Apoptosis and Autophagy of Gastric Epithelial Cells. Front Oncol 2020;10:581364.

47. Byun E, Lim JW, Kim JM, et al. $\alpha$-Lipoic acid inhibits Helicobacter pylori-induced oncogene expression and

Cite this article as: Bi Y, Wu D, Wu X, Wang F, Yu H, Liu P, Cui G, Chen Z. Phycocyanin inhibits Helicobacter pylori-induced hyper-proliferation in AGS cells via activation of the ROS/ MAPK signaling pathway. Ann Transl Med 2022;10(4):176. doi: 10.21037/atm-21-7045 hyperproliferation by suppressing the activation of NADPH oxidase in gastric epithelial cells. Mediators Inflamm 2014;2014:380830.

48. Hao S, Yan Y, Li S, et al. The In Vitro Anti-Tumor Activity of Phycocyanin against Non-Small Cell Lung Cancer Cells. Mar Drugs 2018;16:178.

49. Seo JH, Lim JW, Kim H, et al. Helicobacter pylori in a Korean isolate activates mitogen-activated protein kinases, AP-1, and NF-kappaB and induces chemokine expression in gastric epithelial AGS cells. Lab Invest 2004;84:49-62.

(English Language Editor: A. Kassem) 